\title{
PERFORMANCE EVALUATION MODEL OF THE CLIENT'S MATRIX ORGANIZATION FOR A DESIGN PROJECT
}

\author{
Wei Chih Wang ${ }^{1 *}$, Yueh Hua Lin², Chu Hsuan Chung ${ }^{2}$, Ming Tsung Lee ${ }^{2}$, and Chia Li Lin ${ }^{3}$ \\ ${ }^{1}$ Professor, Department of Civil Engineering, National Chiao Tung University, Taiwan \\ ${ }^{2}$ Graduate Student, Department of Civil Engineering, National Chiao Tung University, Taiwan \\ ${ }^{3}$ Assistant Professor, Taiwan Hospitality \& Tourism College, Hualien, Taiwan \\ *Corresponding author (weichih@faculty.nctu.edu.tw)
}

\begin{abstract}
Conducting a design project of a high-tech facility requires various specialties and rigorous user needs provided from the facility client. Sometime, project client will form a matrix organization with several interrelated functional and projectized divisions to decide those requirements and needs. However, an ill-defined matrix organization very likely causes late and indefinite decisions. Consequently, poor performance of design arises. Identifying the divisions most responsible for the poor performance should support design management. This study proposes a new model to identify key divisions that drive poor performance of design project. In the model, a satisfied importance analysis (SIA) is used to evaluate the performance of each division, while a decision making trial and evaluation laboratory technique (DEMATEL) is applied to capture the causal relationships among divisions to generate an influence-relations map. The model is applied to a real-world high-tech facility design project in Taiwan to indicate the strengths of the model.
\end{abstract}

Keywords: Design Delays, Matrix Organization, Decision Making Trial and Evaluation Laboratory Technique (DEMATEL), High-tech Facility Design Project

\section{INTRODUCTION}

Conducting a design project of a high-tech facility (such a semiconductor facility) requires a variety of specialties (translated into specification requirements) and rigorous user needs provided from the project client. Thus, the project client will need to allocate staffs to provide or review those specific requirements and user needs for supporting the project. Many practitioners and researchers have recognized that how one organizes in managing a design/construction project will have a significant impact on the successful completion of the project [1]. Sometimes, project client may form a matrix organization to play the role when project complexity is extremely high or project scale is large.

A matrix organization structured with ill-defined authorities/responsibilities of various managers very likely causes project client to make late and indefinite decisions.

The importance of efficient design management in ensuring the smooth running of a project is being increasingly appreciated [2,3]. If key divisions that drive the project client's poor performance in design can be identified and attention paid to them, delays can be eliminated or, at least be prevented, from being increased. Nevertheless, identifying the cause-effect relationships among numerous and interrelated divisions and sections is difficult.

This study proposes a new model to identify key divisions that drive project client's poor performance in design. The model is applied to a real-world high-tech facility design project in Taiwan.

\section{PAST STUDIES}

In executing a design / construction project, project client (or owner) often needs to decide two types of decisions related to organization structures. The first type of decision is to determine what project participants should be involved and what the contractual relationships among these participants are [4]. The second type of decision is to 
determine what client's organization should be applied to manage the project. That is, should a functional, matrix, or project-oriented organization be applied? A few researchers have discussed the second type of decision. For example, Thomas et al. [1] describes different organization forms of project management and outlines principles to guide in the establishment of authority and responsibility of the organization. They suggested guidelines to improve chances for success with matrix organization.

The study herein is more related to the second type of decision, which is the focus on the organization structure of project client itself. So far, very little research has noted that identifying significant key divisions of project client's organization can be an efficient strategy for improving the management of design.

\section{PROPOSED MODEL}

The core of the model integrates satisfied importance analysis (SIA) and a decision making trial and evaluation laboratory technique (DEMATEL). Figure 1 presents the systematic steps in the proposed model to identify the divisions and sub-divisions that govern project client's poor performance in a design project.

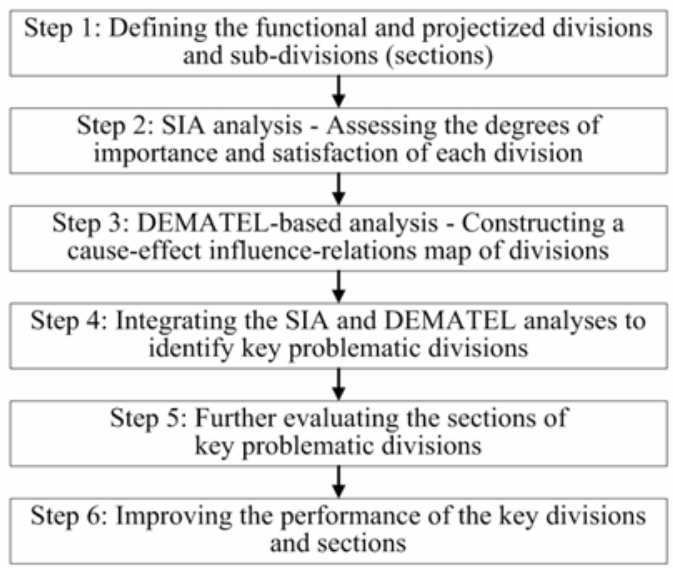

Fig. 1 Steps of proposed model

\section{CASE PROJECT}

The case project is the design and construction of a hightech facility of a national research center located in northern Taiwan. At the beginning of the design phase of the project (called design project hereafter), the client decided to set up a matrix organization because the project size was too large and the required expertise is diverse. Figure 2 displays the client's matrix organization to manage this design project.

As the design project progresses, design is delayed significantly mainly because of project client's poor performance, such as several late decisions and changes of needs issued by the project client. In the midst of this situation, the research team began to implement the proposed model to help identify the problematic divisions/sections to suggest directions hopefully for preventing further delays.

\section{APPLICATION TO CASE PROJECT}

This section first presents the required input data for conducting SIA and DEMATEL analyses, and then describes the analyses in detail.

\subsection{Collection of Input Data}

The required input data for the SIA and DEMATEL are obtained using a set of questionnaires. Thirty-five experts (engineers and managers who were involved in this case project) were asked to fill out each questionnaire. Table 1 shows an example of the questionnaire for executing SIA. Table 2 presents an example questionnaire for performing DEMATEL. Each respondent was asked to evaluate the strength of the direct influence (effect) of a division on each of the other divisions using an integer scale (from zero to four). A high score represents the belief that an improvement in the $\mathrm{AE}$ division relies strongly on an improvement in the ID division. 


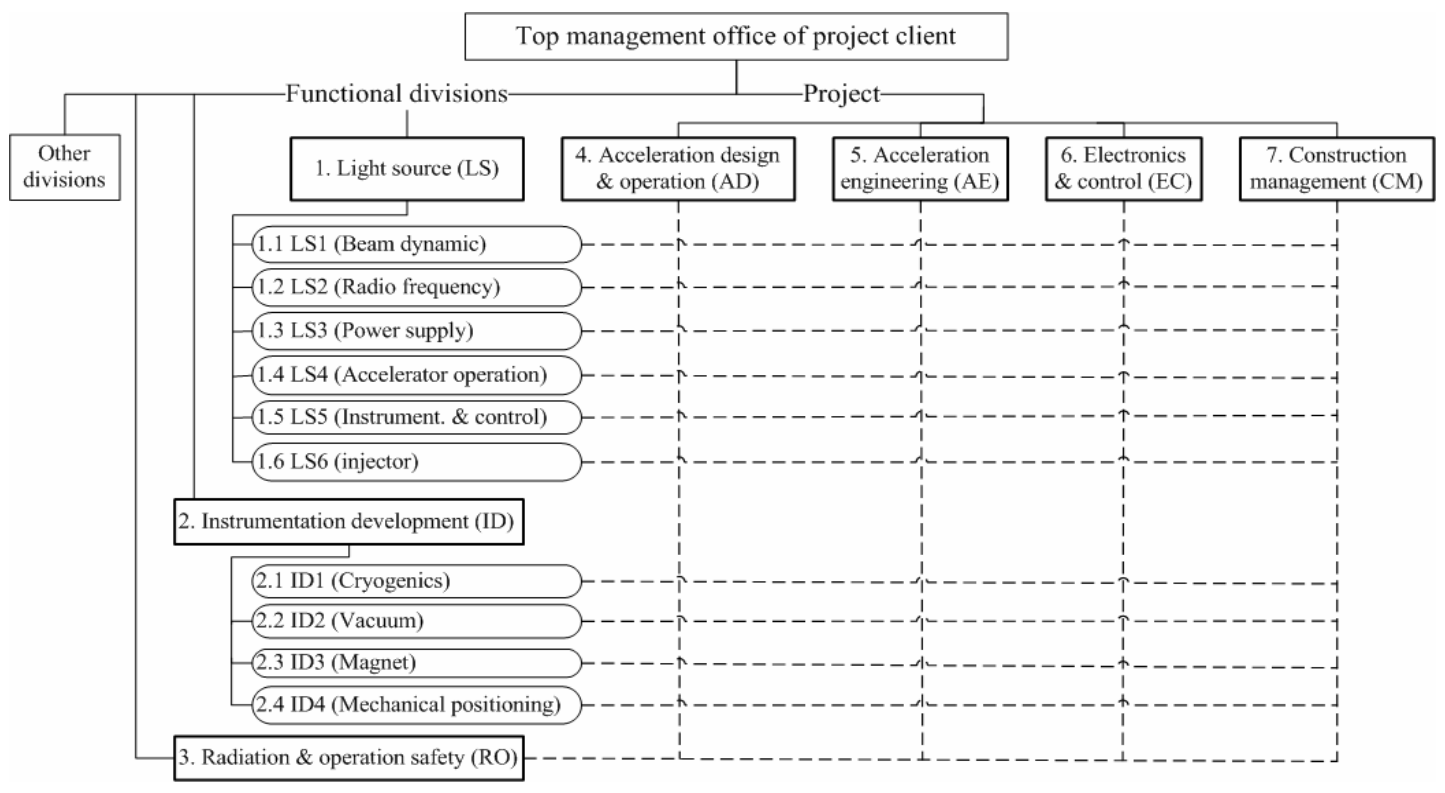

Fig. 2 Client's matrix organization to manage the case project

Table 1. Example of questionnaire for executing SIA

\begin{tabular}{lcc}
\hline Divisions / sections & $\begin{array}{c}\text { Degree of } \\
\text { importance }\end{array}$ & $\begin{array}{c}\text { Degree of } \\
\text { satisfaction }\end{array}$ \\
\hline 1. LS & 7.7 & 5.2 \\
1.1 LS1 & 10 & 8 \\
1.2 LS2 & 8 & 6 \\
1.3 LS3 & 7 & 4 \\
$\ldots$ & $\ldots$ & $\ldots$ \\
7. CM & 9 & 7 \\
\hline
\end{tabular}

Note: Degrees of importance and satisfaction range between ten (highest importance or satisfaction) and zero (lowest importance or satisfaction).

Table 2. Example of questionnaire for generating IRM

\begin{tabular}{|l|c|l|c|c|c|c|c|}
\hline $\begin{array}{l}\text { Division } j \\
\text { Division } i\end{array}$ & $\begin{array}{c}1 . \\
\text { LS }\end{array}$ & $\begin{array}{l}2 . \\
\text { ID }\end{array}$ & $\begin{array}{c}3 . \\
\text { RO }\end{array}$ & $\begin{array}{c}4 . \\
\text { AD }\end{array}$ & $\begin{array}{c}5 . \\
\text { AE }\end{array}$ & $\begin{array}{c}6 . \\
\text { EC }\end{array}$ & $\begin{array}{c}7 . \\
\mathrm{CM}\end{array}$ \\
\hline 1. LS & & & & & 4 & & \\
\hline 2. ID & & & & & 3 & & \\
\hline$\ldots$ & & & & & & & \\
\hline $6 . \mathrm{EC}$ & & & & & & & \\
\hline 7. CM & & & & & & & \\
\hline
\end{tabular}

Note: 0: no influence; 1: weak direct influence; 2: moderate direct influence; 3: strong direct influence; 4: very strong direct influence.

\subsection{Evaluation of SIA}

The SIA method is based on an importance-performance analysis that was proposed by Martilla and James [5]. In the SIA, the input data (degree of satisfaction and degree of importance of each division and section) collected from the questionnaires are normalized to a single measuring scale. Equations (1) and (2) yield the initial degree of satisfaction (IDS) and standardized satisfaction value (SS).

Equations (3) and (4) calculate the initial degree of importance (IDI) and the standardized importance value (SI). The number of respondents in the case study was 35 .

IDS $=\frac{\text { Sum of degrees of satisfaction from all respondents }}{}$

$$
\text { Number of respondents }
$$

$\mathrm{SS}=$ (IDS - Average of initial degrees of satisfaction in all divisions)

IDI $=\frac{\text { Sum of degrees of importance from all respondents }}{\text { Number of respondents }}$

$\mathrm{SI}=\frac{\text { (IDI - Average of initial degrees of importance in all divisions) }}{\text { Standard deviation of initial degrees of importance in all divisions }}$

Table 3 shows the evaluations made using SIA in the case study. The evaluations are classified under the following four categories $(\mathrm{SS}, \mathrm{SI}):(1) \circ(+,+)$ : a division with high satisfaction and high importance. This category is labeled as "keep up good work". (2) • (+,-): a division with high satisfaction and low importance. A division fallen into this category requires no further improvement. However, it is likely that resources invested may better be diverted elsewhere. (3) $\boldsymbol{\nabla}$ (-,-): a division with low satisfaction and low importance. This category is labeled as "low priority". 
(4) $\mathrm{x}(-,+)$ : a division with low satisfaction and high importance. This category is labeled as "concentrate here", indicating the division requires urgent corrective actions.

Table 3. Degrees of satisfaction and importance of $1^{\text {st }}-$ level divisions

\begin{tabular}{|c|c|c|c|c|c|}
\hline \multirow[b]{2}{*}{ Divisions } & \multicolumn{2}{|c|}{$\begin{array}{c}\text { Degree of } \\
\text { satisfaction }\end{array}$} & \multicolumn{2}{|c|}{$\begin{array}{c}\text { Degree of } \\
\text { importance }\end{array}$} & \multirow[b]{2}{*}{$(\mathrm{SS}, \mathrm{SI})$} \\
\hline & $\begin{array}{l}\text { Initial } \\
\text { value }\end{array}$ & SS & $\begin{array}{l}\text { Initial } \\
\text { value }\end{array}$ & SI & \\
\hline 1. LS & 6.790 & -1.218 & 8.200 & -0.970 & $\boldsymbol{\nabla}(-,-)$ \\
\hline 2. ID & 7.179 & 0.243 & 8.200 & -0.970 & - $(+,-)$ \\
\hline 3. $\mathrm{RO}$ & 7.057 & -0.214 & 8.286 & -0.799 & $\nabla(-,-)$ \\
\hline 4. $\mathrm{AD}$ & 7.571 & 1.722 & 9.514 & 1.654 & $\circ(+,+)$ \\
\hline 5. AE & 7.114 & 0.001 & 9.029 & 0.685 & $\circ(+,+)$ \\
\hline 6. $\mathrm{EC}$ & 7.257 & 0.539 & 8.943 & 0.513 & $\circ(+,+)$ \\
\hline 7. $\mathrm{CM}$ & 6.829 & -1.074 & 8.629 & -0.114 & $\nabla(-,-)$ \\
\hline
\end{tabular}

\subsection{Evaluation of DEMATEL}

The DEMATEL method enables management to solve problems visually and to divide the related variables (e.g., divisions or sections) into cause and effect groups to improve understanding of causal relationships among variables $[6,7,8]$. The DEMATEL method is performed based on five steps [8]. See the following illustrations.

Step D1: Finding the average matrix

Suppose $h$ experts are available to solve a complex problem and $n$ divisions are considered. The scores assigned by each expert yield an $n \times n$ non-negative answer matrix $\boldsymbol{X}^{k}$, with $1 \leq k \leq h$. Hence, $\boldsymbol{X}^{1}, \boldsymbol{X}^{2}, \ldots, \boldsymbol{X}^{h}$ are the answer matrices for each of the $h$ experts, and each element of $\boldsymbol{X}^{k}$ is an integer, denoted $\boldsymbol{X}_{i j}^{k}$. The diagonal elements of each answer matrix $\boldsymbol{X}^{k}$ are all set to zero. The $n \times n$ average matrix $\boldsymbol{A}$ can then be computed by averaging the $h$ experts' value (or score) matrices. The $(i, j)$ element of the average matrix $\boldsymbol{A}$ is denoted $a_{i j}$ (average influence),

$a_{i j}=\frac{1}{h} \sum_{k=1}^{h} x_{i j}^{k}$

Table 4 presents an initial average matrix (average matrix A) of the divisions in the case project. The value of $h$ in (5) is 35 ( 35 respondents).

Table 4. Initial average matrix $\boldsymbol{A}$ of divisions

\begin{tabular}{ccccccccc}
\hline Divisions & $1 . \mathrm{LS}$ & 2. ID & $3 . \mathrm{RO}$ & 4. AD & 5. AE & 6. EC & 7. CM & Sum \\
\hline 1. LS & 0 & 1.657 & 1.229 & 2.343 & 1.686 & 2.286 & 1.200 & 10.400 \\
2. ID & 1.543 & 0 & 1.143 & 1.686 & 2.571 & 1.571 & 1.514 & 10.029 \\
3. RO & 1.486 & 1.371 & 0 & 1.571 & 1.571 & 1.486 & 1.800 & 9.286 \\
4. AD & 2.286 & 2.086 & 1.543 & 0 & 2.143 & 2.114 & 1.771 & $\underline{11.943}$ \\
5. AE & 1.686 & 2.657 & 1.257 & 1.829 & 0 & 1.657 & $\underline{2.086}$ & 11.171 \\
6. EC & 1.971 & 1.629 & 1.314 & 1.800 & 1.657 & 0 & 0.943 & 9.314 \\
7. CM & 0.914 & 1.429 & 1.371 & 1.171 & 1.771 & 1.057 & 0 & 7.714 \\
\hline Sum & 9.886 & 10.829 & 7.857 & 10.400 & 11.400 & 10.171 & 9.314 & 11.943 \\
\hline
\end{tabular}

Step D2: Calculating the direct influence matrix

A direct influence matrix $\boldsymbol{D}$ is obtained by normalizing the average matrix $\boldsymbol{A}$. That is,

$\boldsymbol{D}=s \boldsymbol{A}$

where $s$, a constant, is calculated as follows [8];

$$
s=\operatorname{Min}\left[\frac{1}{\max _{1 \leq i \leq n} \sum_{j=1}^{n}\left|a_{i j}\right|}, \frac{1}{\max _{1 \leq j \leq n} \sum_{i=1}^{n}\left|a_{i j}\right|}\right] \quad i, j=1,2, \ldots, n
$$

Step D3: Calculating the indirect influence matrix
The indirect influence matrix ID is obtained from the values in the direct influence matrix $\boldsymbol{D}$. That is,

$$
\boldsymbol{I D}=\boldsymbol{D}^{2}+\boldsymbol{D}^{3}+\ldots=\sum_{i=2}^{\infty} \boldsymbol{D}^{i}=\boldsymbol{D}^{2}(\boldsymbol{I}-\boldsymbol{D})^{-1}
$$

where $I$ is the identity matrix.

Step D4: Deriving the total influence matrix

The total influence matrix $\boldsymbol{T}$ is also an $n \times n$ matrix, and is given by [7],

$\boldsymbol{T}=\boldsymbol{D}+\boldsymbol{I D}=\boldsymbol{D}+\boldsymbol{D}^{2}+\boldsymbol{D}^{3}+\ldots=\sum_{i=1}^{\infty} \boldsymbol{D}^{i}=\boldsymbol{D}(\boldsymbol{I}-\boldsymbol{D})^{-1}$ 
Let $t_{i j}$ be the $(i, j)$ element of matrix $\boldsymbol{T}$; the sum of the $i$-th rows and the sum of the $j$-th columns, $d_{i}$ and $r_{j}$, respectively, are obtained as follows.

$$
\begin{aligned}
& d_{i}=\sum_{i=1}^{n} t_{i j} \quad(i=1,2,3 \ldots, n) \\
& r_{j}=\sum_{j=1}^{n} t_{i j} \quad(j=1,2,3 \ldots, n)
\end{aligned}
$$

Notably, $d_{i}$ represents the sum of the direct and indirect influences of division $i$ on the other divisions, and $r_{j}$ denotes the sum of direct and indirect influences on division $j$ by the other divisions. When $j=i, d_{i}+r_{i}$ is an index of the strength of influences by and on a division, and is a measure of the importance of that division. The term $d_{i}-r_{i}$ (also called "Relation") disaggregates divisions into the "cause group" and the "effect group". If $d_{i}-r_{i}$ is positive, then division $i$ influences other divisions more than it is influenced by, and so belongs to the cause group. Conversely, if $d_{i}-r_{i}$ is negative, then division $i$ is influenced by more divisions than it influences and it belongs to the effect group [8].

\section{Step D5: Obtaining the influence-relations map}

To visualize the complex causal relationships among divisions using a visible structural model, an influencerelations map (IRM) can be developed from the values of $d+r$ and $d-r$, represented on the $x$ axis and the y axis, respectively, of a graph [8].

\subsection{Integration of SIA and DEMATEL}

Integrating the SIA and DEMATEL generates various management strategies to improve the performance of divisions. Some of these strategies are as follows: (1) Strategy A (SS $>0$ and $\mathrm{SI}>0$ ): division requires no further improvement; (2) Strategy $\mathrm{B}(\mathrm{SS}>0$ and $\mathrm{SI}<0)$ : division requires no further improvement; but, its invested may better be diverted elsewhere; (3) Strategy E $(\mathrm{SS}<0$, SI $<0$ and $d-r>0)$ : division must be improved directly with low priority; and (4) Strategy $\mathrm{F}(\mathrm{SS}<0, \mathrm{SI}<0$ and $d-r<0)$ : division must be improved indirectly with low priority. Table 5 presents the evaluation obtained using SIA and DEMATEL. Figure 3 represents the evaluation in visually.

\section{CONCLUSIONS}

This study proposes an innovative model that helps identify the performance and cause-effect relationships among matrix-based divisions of a high-tech facility design project. In the model, the SIA method is adopted to evaluate the performance of each division. A DEMATELbased IRM analysis is employed to analyze the cause-effect interrelationships among divisions. Finally, the SIA and IRM are combined to trace the key divisions that most strongly affect design delays. In the case study, top manager and the project management team appreciated the results of the presented model.

\section{ACKNOWLEDGMENT}

The authors would like to thank the National Science Council of Taiwan (Contract No. NSC99-2221-E-009-132MY2) and the Ministry of Education of Taiwan (via the Aim for the Top University program) for financially supporting this research. The valuable assistance and collaboration of respondents and experts in the case study are greatly appreciated.

\begin{tabular}{|c|c|c|c|c|c|c|c|}
\hline \multirow[b]{2}{*}{ Divisions } & \multirow[b]{2}{*}{$\mathrm{SS}$} & \multicolumn{2}{|c|}{ SIA } & \multicolumn{2}{|c|}{ IRM } & \multirow[b]{2}{*}{ Group } & \multirow[b]{2}{*}{ Strategies } \\
\hline & & SI & $(\mathrm{SS}, \mathrm{SI})$ & $d+r$ & $d-r$ & & \\
\hline 1. LS & -1.218 & -0.970 & $\boldsymbol{\nabla}(-,-)$ & 10.748 & 0.280 & Cause & $\mathrm{E}$ \\
\hline 2. ID & 0.243 & -0.970 & - $(+,-)$ & 11.043 & -0.390 & Effect & B \\
\hline 3. $\mathrm{RO}$ & -0.214 & -0.799 & $\boldsymbol{\nabla}(-,-)$ & 9.135 & 0.672 & Cause & E \\
\hline 4. $\mathrm{AD}$ & 1.722 & 1.654 & $\circ(+,+)$ & 11.622 & 0.695 & Cause & A \\
\hline 5. $\mathrm{AE}$ & 0.001 & 0.685 & $\circ(+,+)$ & 11.715 & -0.153 & Effect & A \\
\hline 6. EC & 0.539 & 0.513 & $\circ(+,+)$ & 10.380 & -0.345 & Effect & A \\
\hline 7. $\mathrm{CM}$ & -1.074 & -0.114 & $\boldsymbol{\nabla}(-,-)$ & 9.119 & -0.759 & Effect & $\mathrm{F}$ \\
\hline
\end{tabular}

Table 5. Suggested strategies for improving performance of divisions 

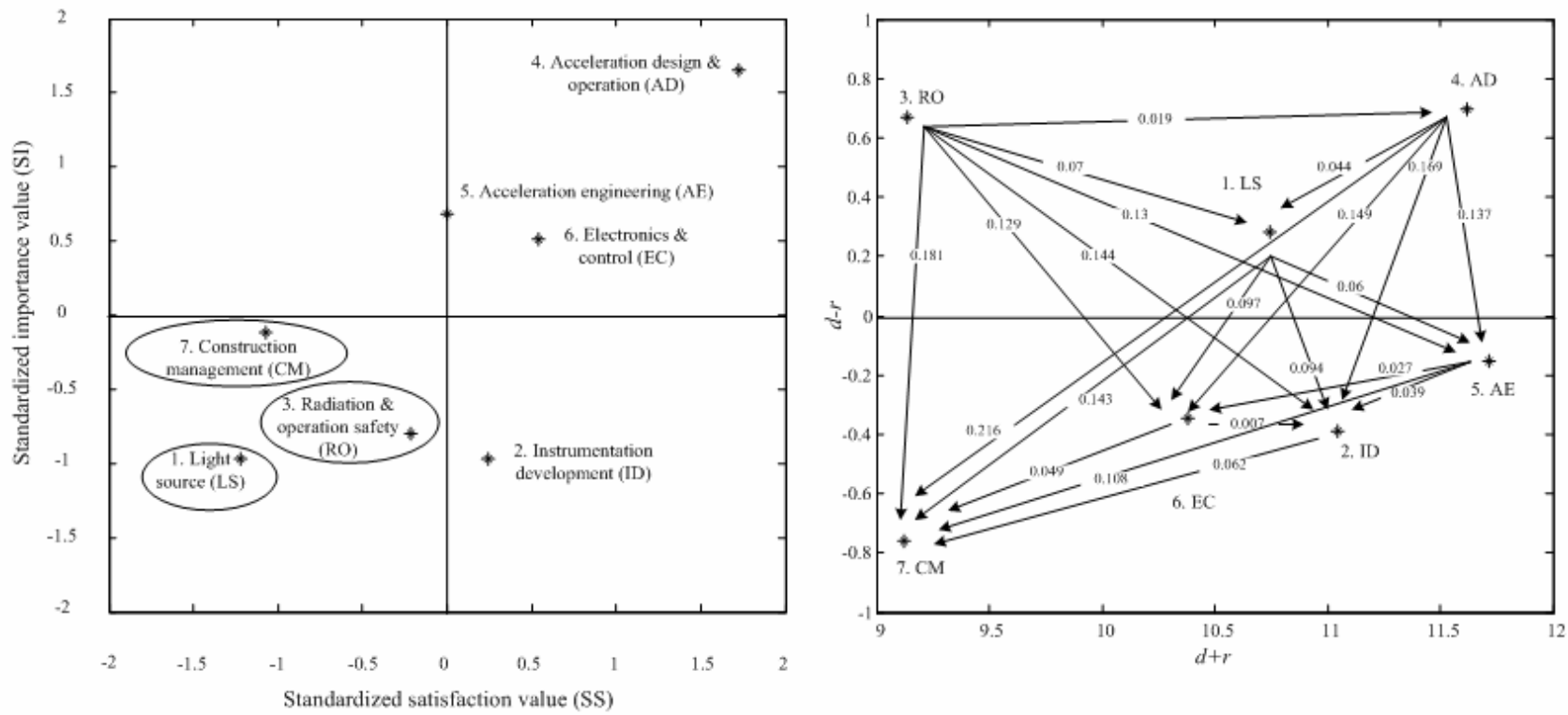

Fig. 3 Integration of SIA and IRM for first-level divisions

\section{REFERENCES}

[1] Thomas, R., Keating, J. M. and Bluedorn, A. C., "Authority structures for construction project management", Journal of Construction Engineering and Management, Vol. 109(4), pp. 406-422, 1983.

[2] Sanvido, V. E. and Norton, K. J., "Integrated designprocess model”, Journal of Management in Engineering, Vol. 10(5), pp. 55-62, 1994.

[3] Senthilkumar, V., Varghese, K., and Chandran, A., "A web-based system for design interface management of construction projects", Automation in Construction, Vol. 19, pp. 197-212, 2010.

[4] Cheng, M. Y., Su, C. W., and You, H. Y., "Optimal Project Organizational Structure for Construction Management", Journal of Construction Engineering and Management, Vol. 129(1), pp. 70-79, 2003.

[5] Martilla, J. A. and James, J. C., "ImportancePerformance Analysis", Journal of Marketing, Vol. 41(1), pp. 77-79, 1977.

[6] Gabus, A. and Fontela, E., Perceptions of the world problematique: Communication procedure, communicating with those bearing collective responsibility, DEMATEL Report No. 1, Geneva, Switzerland, Battelle Geneva Research Center, 1973.
[7] Li, C. W., A Structure Evaluation Model for Technology Policies and Programs, PhD Dissertation, Institute of Management of Technology, National Chiao Tung University, Taiwan, 2009.

[8] Lin, C. L. and Tzeng, G. H., "A value-created system of science (technology) park by using DEMATEL", Expert Systems with Applications, Vol. 36(6), pp. 9683-9697, 2009. 